\title{
Structure of Thin-Film Nickel-Carbon Composites Formed by Microwave Plasma-Enhanced Chemical Vapor Deposition
}

\author{
V. V. Uglov ${ }^{a}$, M. V. Astashynskaya ${ }^{a}$, A. K. Kuleshov ${ }^{a}$, M. P. Samtsov ${ }^{a}$, and P. B. Barna ${ }^{b}$ \\ ${ }^{a}$ Belarus State University, Minsk, Belarus \\ ${ }^{b}$ Research Institute for Technical Physics and Materials Science, Budapest, Hungary
}

Received July 12, 2010

\begin{abstract}
The results of structure research of thin-film nickel-carbon hydrogenated composites formed by the method of the combination of plasma-enhanced chemical vapor deposition of carbon from mixture of reactive gases $\left(\mathrm{Ar}+\mathrm{CH}_{4}\right)$ and physical sputtering of the nickel target are presented. It has been established in the study of composites by transmission electron microscopy that the microstructure of thin-film composites changed from fragmenting columnar to finely dispersed with increase in carbon concentration.
\end{abstract}

DOI: $10.1134 / \mathrm{S} 1027451011080143$

\section{INTRODUCTION}

The incorporation of metal in the carbon matrix is used for the modification of the properties of different carbon materials. This is particularly perspective in the case of amorphous carbon $(a-C)$ films, since they are widely used as ware-resistant coatings in medicine and electronics. It should be noted that $a$-C is a disordered structure consisting of a mixture of carbon atoms with $s p^{2}$ - and $s p^{3}$ - bonds and the portion of the $s p^{3}$-coupled atoms is less than $30 \%$, in contrast to the diamond-like structure characterized by high $(>70 \%)$ content of the $s p^{3}$ - bonds. The distinguishing features of these films are high thermal and chemical stability, as well as their corrosion stability. Recently, a great deal of attention has been paid to the metal-containing amorphous carbon films $(a-\mathrm{C}: \mathrm{Me})$ due to a wide variety of their properties. The advantage of the $a-\mathrm{C}: \mathrm{Me}$ film as an electronic material is that their conductivity changes from dielectric to metallic upon a slight change of their composition. At the same time, the introduction of metal into the amorphous carbon matrix can lead to the reduction of the internal mechanical stresses and increase in the strength and improvement tribological characteristics of the films [1-3].

Many properties of the metal-containing carbon films depend on the nature of the interaction between the atoms of the incorporated metal and carbon atoms. In this respect, it is possible to separate carbide-forming metals ( $\mathrm{Ta}, \mathrm{Fe}, \mathrm{W}, \mathrm{Ni}$ ) and noncarbideforming metals $(\mathrm{Cu}, \mathrm{Au}, \mathrm{Pt})$. The electric properties of such composite materials as $a-\mathrm{C}: \mathrm{H} / \mathrm{Au}$ and $a-\mathrm{C}: \mathrm{H} / \mathrm{Ta}$ were studied by Coberle et al. [4], who demonstrated that the electric conductivity of metal-containing films can be varied 15 -fold by adding the carbon-containing gas $\left(\mathrm{CH}_{4}, \mathrm{C}_{2} \mathrm{H}_{2}\right)$ in the sputtering gas (Ar). It was established that the incorporation of metal in the carbon matrix leads to the formation of clusters or nanocrystalline particles consisting of $\mathrm{TaC}$ and $\mathrm{Au}$, respectively. The concentration and type of the incorporated metal in the hydrocarbon matrix affect the character of the charge transfer process. In the lowconcentration case this can be described by the Mott and Efros models [4].

Schiffmann et al. [4] systematically analyzed the structure of the metal-containing carbon films with both carbide-forming (W, Fe) and noncarbide-forming $(\mathrm{Au}, \mathrm{Pt})$ metals. It was established that, when metal is incorporated in the carbon matrix, the spherical clusters are formed with the average size of $1-5 \mathrm{~nm}$ and located at a distance from each other not exceeding $10 \mathrm{~nm}$. These parameters increased with an increase in the metal concentration in the films. Incorporation of metals characterized by higher melting temperature leads to reduction of the cluster size and the distance between them due to the reduction of the mobility of the metal with higher melting temperature [4].

There are many methods of the formation of metal-containing amorphous carbon films. The process in which physical and plasma-enhanced chemical vapor deposition are combined is the most widespread one [5]. Vapor deposition is based on the magnetron sputtering of a target in the argon atmosphere with addition of carbon-containing gas (methane, acetylene). The flux of atoms of the deposited metal is formed as a result of sputtering of the metal target and hydrogenated amorphous carbon is synthesized by dissociation of the carbon-containing gas in the magnetron plasma and deposition of the hydrocarbon radicals. A feature of this multifunction process is the interconnection of the parameters of the physical and chemical deposition due to the usage of plasma for sputtering of the target and start of dissociation. This leads to a considerable change of the conditions of the sputtering as a result of the chemical reaction between 
carbon and metal on target surfaces. Moreover, the use of different electric excitation of the target strongly affects the microstructure of the obtained thin films. Consequently, this combined deposition process allows one to vary the deposition parameters and the structure and properties of the obtained metal-carbon composites in the wide range [5].

The changes of the structure of hydrogenated nickel-carbon composites formed by the method by plasma-enhanced chemical vapor deposition depending on the carbon concentration in the films were studied in this work.

\section{EXPERIMENTAL}

To deposit composite $\mathrm{Ni} / a-\mathrm{C}: \mathrm{H}$ films on singlecrystal silicon substrates with the (110) orientation, a plasma reactor was used based on the distributed microwave gas discharge (a detailed description is given in [9]). The total current intensity on the nickel target varied from 0.25 to $0.15 \mathrm{~A}$ depending on the concentration of methane $\left(\mathrm{CH}_{4}\right)$ in the gas mixture.

The film thickness and composition was determined by means of Rutherford backscattering spectrometry (RBS) with the use of $\alpha$-particles with an energy of $2 \mathrm{MeV}$ and protons with an energy of $1 \mathrm{MeV}$, the angles of incidence and detection were $90^{\circ}$ and $160^{\circ}$, respectively. The results of these studies showed that the thickness of the $\mathrm{Ni} / a-\mathrm{C}: \mathrm{H}$-films varied in the interval of $400-600 \mathrm{~nm}$. The crystal structure of the films was determined by X-ray analysis on an Inel diffractometer $(\theta / 2 \theta$-scanning $)$ in the range of angles from $20^{\circ}$ to $160^{\circ} \mathrm{Cu} K_{\alpha}$-radiation $(\lambda=1.5406 \AA)$. The Raman spectra were recorded at the room temperature on a Spex 1403 spectrometer equipped with a FEU 928 photoelectron multiplier cooled to the temperature of $243 \mathrm{~K}$. The excitation was produced by an argon laser at a wavelength of $488 \mathrm{~nm}$ at the radiation power on the sample of $0.3-0.35 \mathrm{~W}$.

The method of transmission electron microscopy (TEM) was also used, which allows one to obtain the images of the cross section of a sample, as well as the microdiffraction patterns, which allows the most complete characterization of the structure of studied composites. The electron-microscopic studies of samples were performed on a JEOL 3010 transmission electron microscope at the accelerating voltage of $300 \mathrm{kV}$. In this work the structure of the $\mathrm{Ni} / a-\mathrm{C}: \mathrm{H}$ films was studied depending on the carbon content in them. Since the films of the studied composition were deposited on a silicon single crystal with the (110) orientation and electronograms contained the point reflections from silicon, these reflections were used for the exact determination of the instrument constant, which was used to calculate the interplane distances of the present phases [7].

\section{RESULTS AND THEIR DISCUSSION}

The method of combining the plasma-enhanced chemical vapor deposition of carbon from a mixture of reactive gases $\left(\mathrm{Ar}+\mathrm{CH}_{4}\right)$ and sputtering of a nickel target allows one to obtain nickel-carbon $(\mathrm{Ni} / a-\mathrm{C}: \mathrm{H})$ composites, in which the nickel, carbon, and hydrogen concentrations change depending on the $\mathrm{CH}_{4}$ content in the gas mixture. The concentration data were determined by the Rutherford backscattering spectrometry [11]. The directly proportional dependence of the carbon concentration in the film increasing from 5 to 85 at $\%$ with the increase in the $\mathrm{CH}_{4}$ content in the reactive gas mixture from 0 to $100 \%$.

The structure of composites was studied by X-ray analysis, Raman scattering, and transmission electron microscopy. It was shown in [11] that the phase composition of nickel-carbon composites changes depending on the carbon concentrations in the films. The X-ray pictures of these films show diffraction maxima of nickel $(\mathrm{Ni})$ and nickel carbide $\left(\mathrm{Ni}_{3} \mathrm{C}\right)$, the formation of $\mathrm{Ni}_{3} \mathrm{C}$ occurs at the carbon concentration above 19 at \%. When the carbon concentration increases above 34 at \%, the structure of the composite films becomes X-ray amorphous. The size of Ni crystallites in the films with the carbon content below 19 at \% calculated from the Debye-Scherrer relation does not exceed $5 \mathrm{~nm}$. The size of the $\mathrm{Ni}_{3} \mathrm{C}$ crystallites decreases from 20 to $5 \mathrm{~nm}$ when the carbon concentration increases from 19 to 26 at \%.

The Raman scattering method was used to study the structure of amorphous composites. It was shown in [11] that the size of carbon clusters in the amorphous $a$-C:h-carbon matrix in the films with the carbon concentration above 47 at $\%$ calculated according to the Robertson model [12] is $\sim 1 \mathrm{~nm}$.

The electron-microscopic images of the nickel films formed in the argon gas medium in the absence of methane reveal a fragmented columnar structure (Fig. 1a). The electronogram indicates the polycrystalline structure (Fig. 1b); the calculated interplane distances refer to nickel.

TEM images of the cross section of samples and electron diffraction patterns are shown in Fig. 2. The nickel-carbon composites with the carbon concentration of 8 at $\%$ are characterized by fragmented columnar structure (Fig. 2a). The images show elongated grains; their transverse size is $5 \mathrm{~nm}$, which agrees with the calculated value of the size of nanocrystallites obtained from the X-ray spectra. The redistribution of the intensity over the circumference of the 111 ring is observed in the electronogram indicating the start of the texture formation.

Increase in the carbon content to 19 at $\%$ leads to integration of the columnar structure and its disorientation; the distribution of the diffraction rings indicates the reduction of the texturing degree (Fig. 2b). The films with the carbon content of 26 at \% are mainly characterized by columnar structure (Fig. 2c). 


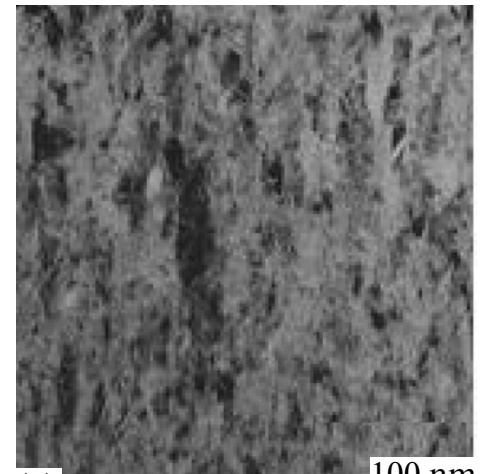

(a)

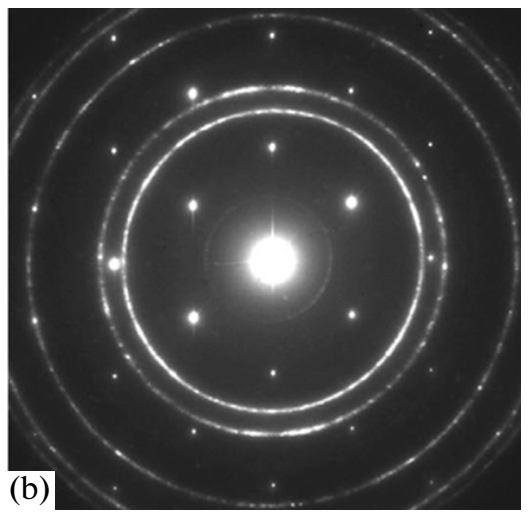

Fig. 1. Light-field TEM image of the cross section (a) and microdiffraction pattern (b) of the nickel film formed in argon.
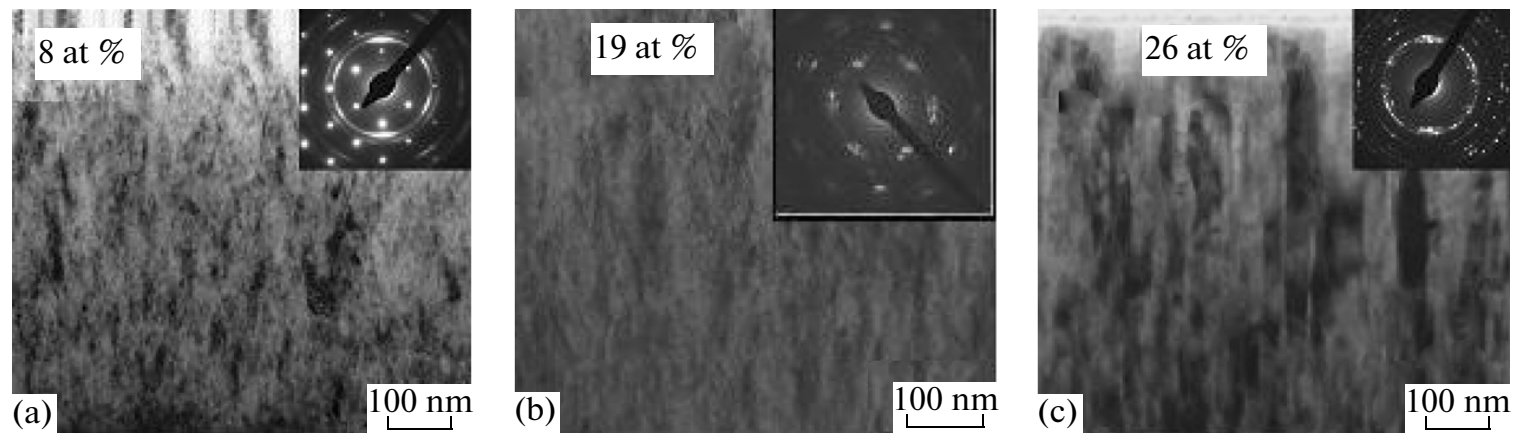

Fig. 2. TEM images of the cross sections $(\mathrm{a}, \mathrm{b}, \mathrm{c})$ and microdiffraction patterns (insets in $\mathrm{a}, \mathrm{b}, \mathrm{c})$ for $\mathrm{Ni} / a-\mathrm{C}: \mathrm{H}$ films with carbon concentration of $8-26$ at $\%$.
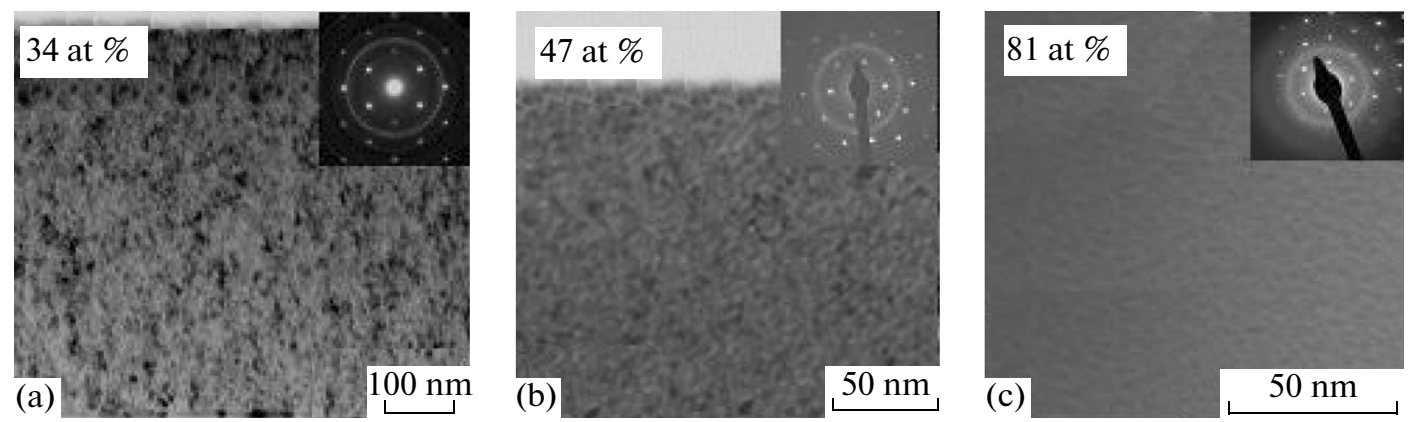

Fig. 3. TEM images of the cross sections $(\mathrm{a}, \mathrm{b}, \mathrm{c})$ and microdiffraction patterns (insets in $\mathrm{a}, \mathrm{b}, \mathrm{c})$ for $\mathrm{Ni} / a$-C:H films with carbon concentration of $34-81$ at $\%$.

The microdiffraction pattern indicates the increase in the disorientation of grains and the layer texturing decreases. A series of rings is displayed in the nickel carbide phase. The further increase in the carbon concentration to 34 at \% leads to a sharp change of the structure of composites from columnar to globular (Fig. 3a). The homogeneous distribution of the intensity in microdiffraction pattern indicates the disappearance of the texture; the interplane distance also refers to the carbide $\mathrm{Ni}_{3} \mathrm{C}$.

The change of the structure of nickel-carbon composites with increase in the carbon concentrations can be explained as follows. At a low carbon concentration (to 8 at \%), nucleation and growth of nickel crystallites occur on the silicon substrate, carbon from the gas phase is most probably dissolved in the Ni crystal lattice. According to the nickel-carbon diagram of state [13], the maximum solubility of carbon in the nickel lattice does not exceed 2.7 at \%; consequently, at a carbon content of 8 at \%, it is possible that the supersaturated solid solution is formed and the carbon atoms are segregated on the boundaries of nickel grains. When the carbon concentration exceeds the solubility limit in nickel and reaches 19 at \%, the carbide phase $\mathrm{Ni}_{3} \mathrm{C}$ 
(a)

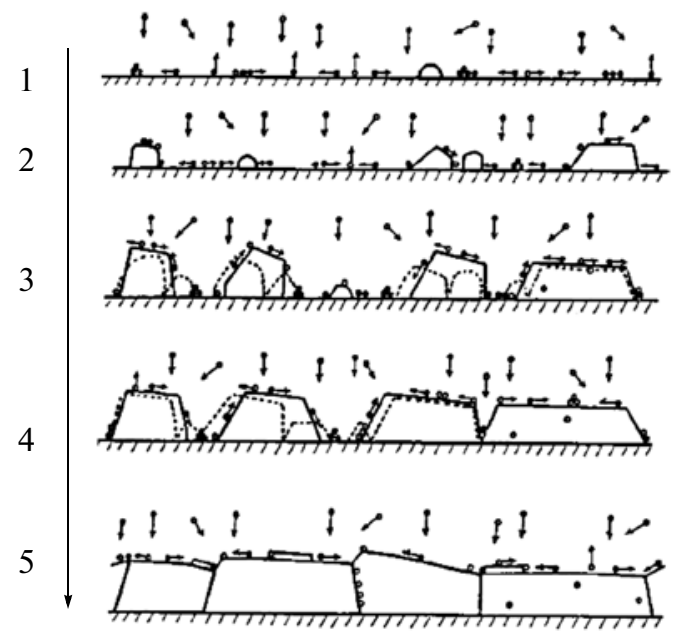

(b)

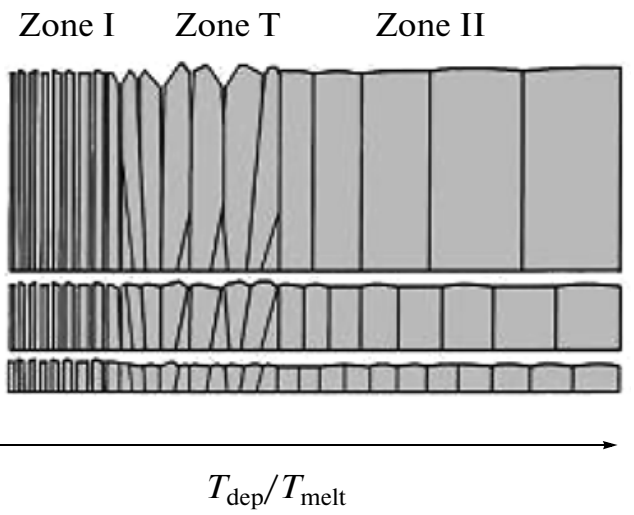

Fig. 4. Schematic images of the process of the film formation (a) and growth (b).

is formed and is segregated on the growing Ni crystals. At the further increase in the carbon concentration above 22 at $\%$, its segregation on the boundaries of $\mathrm{Ni}_{3} \mathrm{C}$ grains leads to the formation of carbon layers on the crystallite surface, as is seen in the pattern of the cross-section columnar structure (Fig. 2c). Increase in the carbon concentration above 34 at \% leads to blocking of further growth of $\mathrm{Ni}_{3} \mathrm{C}$ crystallites, This favors the globular structure with a smaller grain size (Fig. 3a). At carbon concentrations above 47 at $\%$ the structure of the nickel-carbon composites experiences size reduction (Fig. 3b and 3c), it becomes finely dispersed. The sizes of the carbide crystallites for these films were determined from the broadening of the first diffuse maximum in the electronogram [14]. When the carbon content increases to 81 at $\%$, the size of the $\mathrm{Ni}_{3} \mathrm{C}$ crystallites gradually decreases from 7 to $3 \mathrm{~nm}$.

The process of the coating growth when plasmaenhanced chemical vapor deposition of carbon from methane is combined with sputtering of the nickel target can be presented as follows. When the ionized particles interact with the substrate, the centers of crystallization are formed (Fig. 4a). With increase in the size of the particles, they coalesce, leading to the formation of continuous coating [12].

The structure of the formed films is mainly determined by the ratio of deposition temperature to the melting temperature of the film material $\left(T_{\mathrm{dep}} / T_{\text {melt }}\right)$ and the relation between the fluxes of the nonmetal and metal components $\left(J_{\mathrm{C}} / J_{\mathrm{Me}}\right)$ and is described by the structure-band model [13]. When one-component films are formed, their structure is determined by the deposition temperature. At $T_{\text {dep }} / T_{\text {melt }}=0.1-0.2$, as a result of low diffusion mobility of adatoms, the films are mainly formed with the columnar structure (zone I) (Fig. 4b). The increase in the deposition tem- perature $\left(T_{\text {dep }} / T_{\text {melt }}=0.2-0.4\right)$ leads to the activation of the process of the surface diffusion of adatoms that leads to the integration of the columnar structure and its disorientation (zone T). At the further increase in the deposition temperature $\left(T_{\text {dep }} / T_{\text {melt }}=0.4-0.6\right)$ the further integration of the columnar structure occurs due to the three-dimensional diffusion of adatoms (zone II). In the case of the formation of the multicomponent films consisting of nonmetal and metal components, the determining factor that forms the structure is the ratio of the fluxes of these components $\left(J_{\mathrm{C}} / J_{\mathrm{Ni}}\right)$. In this case, the formation of the so-called zone III consisting of the globular equiaxial grains is also possible at the ratio of fluxes $J_{\mathrm{C}} / J_{\mathrm{Ni}} \sim 0.1-1$.

In the case of nickel-carbon composites formed by plasma-enhanced chemical vapor deposition, the structure of the films with the carbon concentration of 26 at \% (Fig. 2c) corresponds to the zone T (Fig. 4b). The globular structure of the films with the carbon content of 34 at \% (Fig. 3a) belongs to the zone III described by the structure-band model [13].

\section{CONCLUSIONS}

It was found that, when $\mathrm{Ni} / \mathrm{a}-\mathrm{C}: \mathrm{H}$ films are formed by the method of plasma-enhanced chemical vapor deposition, their structure is determined by the relation between the fluxes of metal and nonmetal components and the film deposition temperature. The method of transmission electron microscopy allowed us to reveal the change of the structure from fragmenting columnar to the finely dispersed, which corresponds to the zones T and III of the structure-band model. 


\section{REFERENCES}

1. J. L. Endrino, D. Horwat, R. Gago, et al., Solid State Sci. 11, 1742 (2009).

2. N. G. Chechenin, P. N. Chernykh, V. S. Kulikauskas, et al., Poverkhnost', No. 11, 62 (2007) [J. Surf. Invest. 1, 674 (2007)].

3. M. B. Tsetlin, V. G. Nazan, M. N. Rudneva, and V. A. Rogalev, Poverkhnost', No. 12, 94 (2008) [J. Surf. Invest. 2, 923 (2008)].

4. G. Schultes, P. Frey, D. Goettel, and O. Freitag-Weber, Diamond Relat. Mater. 15, 80 (2006).

5. P. Y. Tessier, R. Issaoui, E. LuaisIonized, et al., Solid State Sci. 11, 1824 (2009).

6. Y. Pauleau, F. Thiery, V. V. Uglov, et al., Adv. Mater. Sci., No. 4, 1 (2003).
7. K. Andrews, D. Dyson, and S. Keown, Electron Diffraction Patterns (Plenum, New York 1967; Mir, Moscow, 1971).

8. V. V. Uglov, A. K. Kuleshov, M. V. Astashinskaya, et al., Fiz. Khim. Obrab. Mater., No. 2, 31 (2006).

9. A. C. Ferrari and J. Robertson, Phys. Rev. B 61, 14095 (2000).

10. State Diagrams of Double Metallic Systems, The Manual, vol. 1, Ed. by N. P. Lyakishev (Mashinostroenie, Moscow, 1996) [in Russian].

11. R. Heidenreich, Fundamentals of Transmission Electron Microscopy (Interscience, New York, 1964; Mir, Moscow, 1966).

12. Yu. F. Komnik, Physics of Metallic Films (Atomizdat, Moscow, 1979) [in Russian].

13. I. Petrov, P. B. Barna, L. Hultman, and J. E. Greene, J. Vac. Sci. Technol., A 21, 117 (2005). 